\title{
The 2013 International Psychogeriatric Association Junior Research Awards in Psychogeriatrics
}

Judging for the 2013 International Psychogeriatric Association (IPA) Junior Research Awards in Psychogeriatrics was undertaken by a panel of six experts, selected by the IPA executive, which I had the honor to chair. All three award-winning papers appear in this issue of International Psychogeriatrics immediately following this guest editorial. I am confident that, like their many predecessors awarded over more than two decades, they will be highly cited (Pachana, 2012) and will be seen in due course as crucial to the development of the young and very promising researchers who have received this prestigious acknowledgment of their excellent work.

Apart from myself, the judging panel consisted of Nicola Lautenschlager, Editor-in-Chief of International Psychogeriatrics (Australia), Jiska CohenMansfield (Israel), Chang Uk Lee (Republic of Korea), Kang Seob Oh (Republic of Korea), and Anne Margriet Pot (the Netherlands). Eleven entries were received from Australia, China, India, Japan, the Netherlands, the Republic of Korea, Singapore, Uganda, and the United Kingdom of Great Britain and Northern Ireland; at the time of submission, the Korean candidate was working in the United States of America and the Singaporean candidate was enrolled for a $\mathrm{PhD}$ with an Australian university. During the judging process the assessors were kept blind to the names and affiliations of the contenders.

The six judges first marked each paper on a sixpoint scale. These marks were averaged. Four papers scored substantially better than the other seven and the judges were asked to re-evaluate each of these four submissions and to rank them from one (most deserving for first prize) to four. Once again, the paper placed fourth in the initial voting was allocated the fourth position in this final process, and there was a clear and unambiguous result obtained for all four places. The following were the three winning papers: from Newcastle-upon-Tyne, UK (first place), John-Paul Taylor et al. (2013) "Covariant perfusion patterns provide clues to the origin of cognitive fluctuations and attentional dysfunction in Dementia with Lewy bodies"; from Suwon City, Republic of Korea and Pittsburgh PA, USA (second place), Hyun Kook Lim et al. (2013) "Aberrant topographical organization in gray matter structural network in late life depression: a graph theoretical analysis"; and from Heerlen, the Netherlands (third place), Ruslan Leontjevas et al. (2013) "More insight into the concept of apathy: a multidisciplinary depression management program has different effects on depressive symptoms and on apathy in nursing homes." Several of the remaining eight papers were considered by the judges to be suitable for possible publication in a regular issue of the journal, and those authors have been invited to re-submit their papers for consideration as original research articles. We hope that several of them will be accepted for publication following due process.

It is notable that for the second round of awards running, two of the winners were the authors of neuroimaging papers. In the 2011 awards, the second and third place winning papers by Allan et al. (2012) and Watson et al. (2012) dealt respectively with white matter change in late life depression and gray matter changes in Dementia with Lewy bodies (DLB). Indeed, the paper of Taylor et al. (2013) is the second DLB imaging paper from Newcastle-upon-Tyne to win an award in two consecutive award rounds.

One of IPA's main roles is to advance the discipline of Psychogeriatrics. The IPA Junior Research Awards do exactly that in every IPA Congress year, and I congratulate not only our three worthy award recipients but also IPA itself for creating and sustaining this process over a quarter of century. My heartfelt and sincere thanks are due to our hardworking panel of judges, who gave up their scarce and valuable time to assess all 11 entries, and to Molly Laurence at IPA headquarters, who did a splendid and unfailingly cheerful job of coordinating the whole affair.

\section{DAVID AMES}

International Psychogeriatrics Book Review Editor and former Editor-in-Chief, Judging Panel Chairman for the 2013 IPA Junior Research Awards in Psychogeriatrics, National Ageing Research Institute and Department of Psychiatry, University of Melbourne, Parkville, Victoria, Australia

Email: dames@unimelb.edu.au 


\section{References}

Allan, C. L. et al. (2012). Does the Framingham Stroke Risk Profile predict white matter changes in late-life depression? International Psychogeriatrics, 24, 524-531. doi:10.1017/S1041610211002183.

Leontjevas, R. et al. (2013). More insight into the concept of apathy: a multidisciplinary depression management program has different effects on depressive symptoms and on apathy in nursing homes. International Psychogeriatrics, 25, 1941-1952. doi:10.1017/S1041610213001440.

Lim, H. K., Jung, W. S. and Aizenstein, H. J. (2013). Aberrant topographical organization in gray matter structural network in late life depression: a graph theoretical analysis. International Psychogeriatrics, 25, 1929-1940. doi:10.1017/S104161021300149X.

Pachana, A. (2012). The 2011 IPA Junior Research Awards in Psychogeriatrics. International Psychogeriatrics, 24, 513-514. doi:10.1017/S1041610211002213.

Taylor, J.-P., Colloby, S.-J., McKeith, I. G. and O'Brien, J. T. (2013). Covariant perfusion patterns provide clues to the origin of cognitive fluctuations and attentional dysfunction in Dementia with Lewy bodies. International Psychogeriatrics, 25, 1917-1928. doi: $10.1017 /$ S1041610213001488.

Watson, R., O'Brien, J. T., Barber, R. and Blamire, M. M. (2012). Patterns of gray matter atrophy in Dementia with Lewy bodies: a voxel-based morphometry study. International Psychogeriatrics, 24, 532-540. doi: $10.1017 / \mathrm{S} 1041610211002171$ 